\title{
Transforming Collections: Reflections on Challenges for Academic Health Libraries ${ }^{1}$
}

\author{
Pamela S. Morgan
}

\begin{abstract}
Libraries are continually challenged when it comes to the preservation and development of their collections, from ancient libraries and their collections of unique items to modern libraries with their large collections of mass-produced items. Beyond printing technology and resource availability, the challenges shaping collection development today include electronic resources, shifting publishing models, changing user expectations, and grim economic realities. This column discusses these challenges as they pertain to academic health libraries and reflects on the approaches that libraries are taking to address them.
\end{abstract}

\section{Where are we now?}

When libraries consisted entirely of print collections, each library purchased what was core to them and borrowed from one another to supplement their collections. When collections switched to electronic, user expectations also switched, particularly their definition of available. Instead of coming to the library, users expect the resources to be available to them at the click of a button, anytime and anywhere. Anything less has become a frustration. One service that libraries use to meet this "instantaneous" expectation is the desktop delivery of articles. The changes in copyright and, particularly within Canada, a shared document delivery system allow libraries to send articles directly to a user's email. Desktop delivery of articles has greatly improved turnaround times and appeased many users, but there are other options for desktop delivery besides traditional interlibrary loan (ILL) including payper-view (PPV) direct from the publisher. A much more expensive option, PPV does not appear sustainable as a replacement for licensed resources unless tightly controlled by targeting peripheral journals or the highly specialized titles required by a select few. Students and faculty have also found ways to bypass the library altogether. Technology is taking personal networking, such as emailing the author for a copy, to another level. For example, the "\#icanhazpdf" twitter feed consists simply of requests from people for others to supply them with a copy of an article, regardless of the legality.

Although this works for articles, many academic libraries are using a patron-driven or demand-driven acquisition (PDA/DDA) model for electronic books. You can load an entire e-book collection into your discovery service and pay a short-term loan (STL) fee whenever someone uses the book, with "use" being strictly defined. After a certain number of STLs, the library must buy the book. Users do not need to know if the library owns the book, and collections librarians can leave the decision to users when debating the value of a particular title or choosing between two similar titles. Acquisitions departments, however, encounter difficulties as publishers constantly change prices for the book and the STLs without notice and they withdraw titles from PDA/DDA availability.

Resource discovery tools and the internet have increased a user's ability to identify materials they may want, but with the growth in publishing and the ease of searching, no library can afford either the dollars or the space to own everything that the user might come across. Libraries have always shared their collections. The benefits of resource sharing are easy to talk about - a shared virtual collection, sharing of the cost burden, and an ability to focus collections on specific needs and supplement with peripheral titles. However, there are limits to resource sharing beyond the time involved. Some licenses mention interlibrary loan in terms of "own country", if they allow it at all. Reciprocal arrangements between libraries to decrease turnaround time and ensure reliable access may risk opening the library to charges of collusion. There is no technical way for an academic library to lend its e-book to another library or even to a nonprimary patron such as a physician in an associated teaching hospital. Libraries with space issues have moved titles to off-site storage. However, it costs money not only to house resources but also to retrieve them from storage whether for your own patron or for another library. Finally, the more Big Deals or packages that

Pamela Morgan. ${ }^{2}$ Health Sciences Library, Memorial University of Newfoundland, Health Sciences Centre, St. John's, NL A1B 3V6.

${ }^{1}$ This is a condensed version of a paper preszented to the AFMC Libraries Group during their meetings at the Canadian Conference on Medical Education, 24 April 2015.

${ }^{2}$ Corresponding author (email: pmorgan@mun.ca) 
libraries are involved with, particularly on the national consortia scale, the fewer resources are unique.

Besides ILL and consortia, there are other types of collaboration in which libraries must be involved. The more that education goes electronic, the more the library needs to develop its relationships with other departments in the university. These include computing communications departments, distance learning departments, instructional technology groups, copyright offices, research offices, and publishing divisions. And who is responsible for such matters as institutional repositories, digital archives, electronic theses, electronic reading lists, open journal systems, and open author funds? Clifford Lynch [1] said "So much of the new content is outside of the library and outside of the entire system of publishing that it is unclear how much responsibility the libraries can or should take for this material or how they should go about taking that responsibility" (p. 66).

On an external basis, libraries can develop collaborative efforts through the establishment of cooperative collection policies and the development of best practice guidelines such as the University of Alberta's statement on nondisclosure clauses [2]. We need to ask ourselves (and find the answers for) questions such as: Who is collecting comprehensively in an area and who is selective? Who is preserving the last print copy or the last electronic copy? Who has digitized it? Who is specializing in what area? Perhaps we first need to determine whether there still a need to "collect" to preserve a field of knowledge, or is the need simply to get what is needed by users? Libraries also need to build relationships with the vendors, to treat them as partners and not as adversaries. It is only through long-term relationships that libraries can hope for the flexibility to see them through the tough times. We also need to collaborate with publishers so they better understand academic publishing models, deal with new technologies, and work with libraries to benefit all.

Collection assessment is often overlooked, particularly when so much is tied into packages. One of the positives of the Big Deal [3] was that collections librarians no longer had to perform the labour-intensive task of selecting, reviewing, and weeding each and every title to which a library subscribed. Few libraries continued to undertake these time-consuming assessments. When time is at a premium, this is one thing that was easy to stop but has resulted in a scarcity of data that are now needed as libraries try to regain control over the collection.

The big problem with The Big Deal relates to budgets and inflation. Canadian libraries today consider themselves fortunate if they receive a flat budget. No library is getting annual $4 \%-10 \%$ increases in their materials budget, but publishers are increasing their prices this much every year, not accounting for exchange rates. There is simply no way for a library to keep up with the price increases. Libraries have already taken steps such as changing the percentage of spend on monographs versus serials, curtailing binding, cutting duplicates across branches, eliminating standing orders, cutting non-package resources, and perhaps even running deficits and using staffing vacancies to achieve zero-based budgeting - all to try and maintain the Big Deals.
The current Open Access (OA) model is just as unsustainable. In its conception, this idea had potential. The academics doing the research, the peer review, and the editorial work disseminate their research for free and their institutions do not have to pay to access it. However, in some ways this movement has been taken over by the publishers, with a variety of author fees now being levied. In the first three years of operation at Memorial University, the spend on the Open Access Author's Fund grew approximately $500 \%$, with medical faculty being among the top users. These fees are often paid by the library out of existing materials budgets, limiting the flexibility of the library to strategically acquire resources.

Cancellations of Big Deals are tricky and bring back into play the concept of collaboration. Large multidisciplinary packages require cooperation across all disciplines to purchase them, and each discipline does its own assessment as to whether or not they are getting their money's worth. The problem with collaboration on a small scale within one institution - what happens if one discipline wants to cancel Package A and another wants to cancel Package B - becomes exponentially larger when expanded out to consortia deals and multi-institutional partnerships. As well, there may be a discount for subscribing to multiple packages from one provider, so cancelling one package simply increases the cost of the remaining packages. Publishers also bundle titles together into exclusive packages whereby the only way to get a specific title is to buy the entire package. They continue to add more resources to the packages, increasing the price. Publishers do not seem to understand that the number of additional resources is immaterial if a library does not have the money.

Decisions to cancel are fraught with minefields. Librarians must have some evidence behind their decisions, some unbiased criteria. However, usage statistics are only one factor in determining whether the library should subscribe to a title or not. This quantitative evidence must be balanced against the context. Terry Bucknell's paper entitled "Garbage in, gospel out: Twelve reasons why librarians should not accept cost-per-download figures at face value" [4] details why you need a caveat on usage statistics and highlights the need to balance quantitative and qualitative information. Even with this data, librarians will face the wrath of faculty members as favourite titles are cut. William Birdsall [5] noted in 1998 that it would not matter how much evidence you had, a faculty member would not accept it because of the implied criticism of their scholarship. His conclusion was that cancellations can only be dealt with through economic discussions with faculty.

Another group with whom communication is important is the administration within faculties of medicine. They have to understand the difference between a library purchasing a journal package and a laboratory purchasing a microscope. For libraries, monies are committed long before some budget decisions and by fiscal year-end, there is nothing left to cut. It may be a consortia deal that has been six months in negotiation, it may be a multi-year deal, it may be a vendor contract with a 60 day cancellation notice period; the timing of renewals is a factor - a library cannot defer renewing a subscription for a few months. 


\section{Where do we go from here?}

I believe we will see smaller selective deals and increased individual selection on the journals side. Strong collaboration with faculty will need to be coupled with the librarians' judgement backed by usage statistics from both electronic platforms and document delivery. Package and individual purchases of e-books selected by librarians will continue to be balanced with PDA for the next few years, at least until the market and publishers gain more experience and PDA settles into a mature product. Whether it remains or falls by the wayside will not only depend on the publishers, but also on guidelines that libraries should and need to develop. Nonetheless, I think we will see a retreat from the movement to wholly virtual libraries back to stronger print collections-with the exception of mobile applications.

Collections across the country will no longer be as homogenous as they have become under the Big Deals, but they will develop strengths in certain areas. We will have a greater emphasis on unique materials that are local to the institution such as digital repositories, e-theses, learning objects banks, reading lists, datasets, and digitization of archives and special collections, and the library as the publisher or stakeholder for OA journals - essentially making unique collections that distinguish one library from another. As such, we will have increased emphasis on resource sharing.

There will still be a role for collections librarians. Although the actual selection of titles and liaison with faculty will be spread out, specialized collections librarians will be more involved in assessment, and libraries will continue to hire scholarly communication librarians to find ways to collect the academic output of the university through repositories and to encourage true OA models of "publishing."

In closing, there are a variety of collections dichotomies on which we can reflect. The discussion has turned from serials versus monographs format decisions into continuation order versus firm order decisions. Almost everything that the library now buys is a continuation or subscription, even a large portion of books and audio-visual material. The resources that are purchased outright are few. Becoming scarcer still is the stand-alone title, as many titles now are bundled into packages. For most libraries now, the bundle is an irritation at best and a straitjacket at worst. In addition, if resources are electronic, there may be ongoing costs attached in the form of maintenance fees for current and (or) perpetual access. Even print versus electronic is still an argument today. People want to be able to choose what suits them at a particular point in time. The container is merely the tool and people want to use whatever tool is most convenient and do not understand why the library restricts them to one or the other. Economics and licenses will dictate what a library can provide.

The question of who is selecting the materials, users versus librarians, sparks discussion as to how a balanced collection is maintained or whether it is even needed. This relates to the age-old debate of ownership versus access and the question of whether the library should own the material or rely on resource sharing. Do we need to collect for the future, for the enduring knowledge bestowed by collections, or do we simply provide what is needed at the time and hope it is available somewhere when next it is needed?

Today's focus on the article as the commodity introduces the dichotomy of collection development versus content development; if a library buys access to an article for one patron, how can they manage this content in the assumption that another patron will also be interested in the same content? Many born digital e-journals are publishing articles, identified by article numbers, and they not bundling the articles into volumes and issues.

OA versus PPV reflects a difference in access models and looks at who pays and when. Unless the faculty, caught in their own "publish or perish" dichotomy, take a stand it is unlikely that OA will succeed. Thus, the library is caught between author fees, author funds, research grants, and subscriptions. How can libraries obtain a share of the research monies that have been allocated for OA publishing to finance OA authors' funds? How can libraries best collect the research output of their researchers?

Academic librarians are faced with the additional challenge of research versus teaching; where should the bulk of the budget for an academic health library go? Students, who are the reason for the medical school to exist, rely on the library and have generally homogenous needs. Researchers bring in the money and have very specific needs in very concentrated topics, but they also have access to grants and collegial networks.

And so the overall responsibilities for collections, defined formerly as collection development, transforms into collection management, reflecting the depth and breadth of issues surrounding collections. No longer expert bibliographers selecting and weeding titles, collections work has grown to encompass licensing and negotiating, preservation, digitization, OA, and scholarly publishing. The library will continue to collect resources for its primary users, but the collection will not be aligned around the format or container. It will be focused on the discrete content, on managing the output of the institution, and in collaborative efforts to widely share the limited resources it is able to purchase or license.

\section{References}

1. Lynch C. From automation to transformation: forty years of libraries and information technology in higher education. Educause Educ. Review. 2000;35(1):60-68 [Internet]. Available from: https://net.educause.edu/ir/library/pdf/ERM0018.pdf

2. University of Alberta Libraries Statement of Principle on Non-disclosure Clauses in Licenses [Internet]. Edmonton, AB: University of Alberta Libraries; [updated 9 September 2014; cited 31 July 2015]. Available from: http://www.library.ualberta. ca/aboutus/collection/disclosure/

3. Rolnik Z. Big deal = good deal? Ser Libr. 2009;57(3):194-198. doi: 10.1080/03615260902913087.

4. Bucknell T. Garbage in, gospel out: twelve reasons why librarians should not accept cost-per-download figures at face value. Ser Libr. 2012;63(2):192-212. doi: 10.1080/0361526X.2012. 680687.

5. Birdsall WF. I am read, therefore I am: faculty and the psychology of journal cancellations. J. Acad. Librariansh. 1998; 24(3):240-241. doi: 10.1016/S0099-1333(98)90046-5. 